PROGRAM DIRECTOR'S NOTEBOOK

HELEN H. BAKER, PhD, SECTION EDITOR

\title{
Recruiting interns and residents to an osteopathic medical training program
}

\author{
GARY L. SLICK, DO
}

As more graduates of colleges of osteopathic medicine enroll in allopathic training programs and specialty programs, medical directors of osteopathic medical institutions are faced with the challenge of maintaining a welltrained housestaff. More important, perhaps, this exodus threatens the very core of osteopathic medicine, namely, its ability to produce well-trained primary care physicians. A recruitment plan used at the Chicago College of Osteopathic Medicine and its affiliates is presented here. The plan emphasizes the importance of trainee involvement in their own education as well as the use of residents in recruiting interns and specialty residents.

(Key words: Intern training, resident training, internship, residency, osteopathic medicine, Chicago College of Osteopathic Medicine)

For several years, it has been common knowledge that a progressive exodus of osteopathic medical students and interns to allopathic training programs has been occurring. At the same time, a documented increase in the number of osteopathic medical students and interns entering training programs in nonprimary care areas has been noted. This latter fact strikes at the core of the osteopathic medical profes-

Dr Slick is professor and chairman, the Department of Internal Medicine, Chicago College of Osteopathic Medicine, Chicago, Ill.

Reprint requests to Gary L. Slick, DO, Department of Internal Medicine, Chicago College of Osteopathic Medicine, $5200 \mathrm{~S}$ Ellis Ave, Chicago, IL 60615. sion, namely, its expertise in producing primary care physicians. These trends, together with the need to maintain quality housestaff, have influenced the program director's ability to fill training programs.

Recognizing this fact, the Chicago College of Osteopathic Medicine and Medical Centers (CCOM-MC) began an organized recruitment program in 1989. Its objective was to attract high-quality trainees to the various residency programs in the institution. The methods described herein are those used by the institution as a whole as well as those specific methods tailored to the internal medicine residency program and internal medicine specialty track internship program.

\section{CCOM-MC Task Force plan for student recruitment}

This Recruitment Task Force plan had two primary objectives: Recruit osteopathic medical students to enroll in clerkship electives at CCOM-MC, and provide a quality learning experience that would affect the students' decision to select CCOM-MC for a traditional or specialty track internship.

The Task Force first identified problems contributing to the inability to effectively recruit students. A plan of action was then developed to resolve those problems that could be corrected. Problems that were unresolvable were not acted on.

Our recruitment efforts were aimed toward those schools that have traditionally sent significant numbers of students for elective clerkships at CCOM-MC. Members of the CCOMMC faculty who were alumni of the targeted 
schools made the recruitment trips. Each CCOM-MC department identified the maximum number of additional students that could be accommodated on individual services without sacrificing the quality of the learning experience.

Certain factors that previously discouraged students from taking electives at our institution were identified and corrected accordingly. Adequate living quarters, proper orientation procedures, and personal attention provided by program directors and faculty are examples of the improvements made.

\section{Methods used for students on elective rotations}

Providing as pleasant an atmosphere as possible with a high-quality learning experience is vital once students arrive at our institution. Making students feel welcome and that they are an important part of the teaching program is a significant aspect in fostering this friendly environment.

As such, students are first introduced to the director of medical education (DME), at which time they are oriented and made to feel welcome. The department chairman of the service from which the clerkship has been selected is introduced as well. Additional specific introductions to specific department personnel are made at this time.

Each student's responsibilities are reviewed on an individual basis. Students on an external clerkship should be assigned the same responsibilities as those students who use the institution as their base hospital. Students are encouraged to stop by the department office at any time with inquiries or problems that may arise.

An exit interview with the DME and the department chairman or program director completes the recruitment process. A friendly atmosphere should pervade the interview session. Students should be encouraged to mention not only the positive aspects of their experience, but also any negative aspects that they feel should be corrected for the rotation to be a better learning experience. The exit interview serves as a forum in which students can have input in their education system; they then have a feeling that their opinions and evaluation are important to the training institution.

If students express an interest in a particular specialty track internship or residency program for the future, the DME or program director should discuss this program at this time, if not earlier.

\section{Recruiting specialty tract interns for residency positions}

Preliminary data indicate that the specialty track internship program has been very successful in attracting osteopathic medical graduates. However, the exodus of specialty track interns to allopathic residency programs after they complete their first year of postgraduate training proves disheartening to program directors, especially those of us in internal medicine.

The quality of the teaching program and the methods used to maintain specialty track interns' interest determine if said interns remain in their corresponding residency program. The internal medicine residency program at CCOM has been successful, to date, in maintaining such interns in the internal medicine residency program. Our success has been partially related to a quality specialty track internship program directed toward future residents in internal medicine. At the same time, our program provides a friendly, but challenging, learning environment.

Conveying the message to the specialty track interns that they are integral members in the department and the residency program helps to maintain a constancy within the training program. Interns are treated as if they were already residents in training.

As such, interns on an internal medicine rotation are required to attend all educational conferences that are available to the internal medicine residents. The interns can become active participants in the Medical Resident Journal Clubs, morning reports, and other activities afforded residents. The department holds quarterly meetings at a local restaurant; interns are invited. Other special luncheon conferences made available to residents are also open to interns. 
Not only are interns, for the most part, offered the same educational opportunities as residents, they are also evaluated in a similar way.

The training program for specialty track interns should be distinct from those training programs offered other interns. Such a program should prove advantageous to the internal medicine intern's future practice. A quality program must address the perception that training in an allopathic medical institution "across the street" is somehow better. To that end, CCOM established an agreement with a respected university-affiliated training program. Our interns spend 2 to 3 months each year at that institution.

This strategy makes trainees aware of the institution's concern for the quality of their training and proves, through affiliate-site training, that the osteopathic medical institution offers a comparative program. This message will then be conveyed to future applicants. For this reason, overcoming the "grass-is-alwaysgreener-on-the-other-side" perception is vital to successful recruitment.

Interns seeking a specialty track program should undergo a separate application process from those interns seeking a traditional track. A departmental committee should conduct the potential trainees' interview. In this way, the interns feel at the outset as if they are already part of the training program.

Being able to foresee potential problems and making adjustments to avert these difficulties help to keep trainees content. Conflicts may arise when these specialty track interns are on rotations in noninternal medicine services. In such instances, specialty track interns' responsibilities may differ slightly from traditional interns' duties on that particular service. For example, specialty track interns are required to leave a service one-half day per week to attend an ambulatory-care clinic. This absence may cause problems within other departments. Therefore, other departments should be informed of the different duties as- sociated with the specialty track training so that they may take these differences into consideration when they plan their program.

As part of this plan, the program director should inform all department members whom they will supervise during the upcoming training year. Nothing is more embarrassing for department members or discouraging for the interns than for either party to be unaware of the other.

Many of the points described herein seem minor, but factors such as these often affect the trainees' final decision to select a program. Certainly, competitive compensation-salary and fringe benefits-is another important consideration influencing the trainees' choice.

\section{Residents' role in recruitment process}

Residents' attitudes play a key role in attracting students to specialty track internships and interns to residency programs. A contented resident class, one who is satisfied with its training, makes for a successful "sales team." We at CCOM-MC have been most successful in our recruitment efforts in those years when the resident class has expressed relative contentment and satisfaction in their learning experiences. Because of residents' invaluable spokesmanship for osteopathic medical training programs, the department should make every effort to include them in the recruitment process. Along those lines, potential applicants should be encouraged to seek out residents for their evaluation of the training program. A good word or two from the residents will do much to convince the students and interns (or both) that this institution is the place to train.

\section{Comment}

Making the training environment friendlybut challenging-and allowing students, interns, and residents active participation in the education programs fosters a sense of loyalty that will ensure a highly trained, constant housestaff. 